\title{
A síndrome do vestiário
}

Cálide Soares Gomes*

A síndrome do vestiário, ou temor, vergonha ou inibição de tomar banho, trocar de roupa ou urinar em companhia de outros homens é bem mais freqüente do que se imagina, embora não existam estatísticas a respeito. Seus acometidos são homens incomodados com as dimensões ou aspecto estético de seus pênis, geralmente, em estado de flacidez, que evitam desnudá-los na presença de outros homens. Até que ponto isso é procedente? Do ponto de vista desses indivíduos, o homem deve possuir um pênis grande, grande o suficiente para, em flacidez, não "envergonhá-los" perante outros e em ereção, volumoso o bastante para "impressionar" a parceira sexual. Do ponto de vista antropométrico, excluindo-se os pênis hipoplásicos e os mal-formados congenitamente, vários estudos demonstraram que o comprimento médio do pênis do homem adulto situa-se entre 8,5 e $9,4 \mathrm{~cm}$ em flacidez e entre 12,9 e 14,1 cm em ereção. Ainda, segundo a Associação Americana de Urologia, o micropênis adulto é o que mede menos de $4,0 \mathrm{~cm}$ em flacidez ou menos de $7,5 \mathrm{~cm}$ em ereção. Fisiológicamente, praticamente qualquer pênis considerado normal, adapta-se a quase todas as vaginas

* Médico urologista. Professor auxiliar da disciplina de Clínica Cirúrgica (Urologia) da Faculdade de Medicina da UFMA. 
normais e é capaz de eficientemente estimulá-las. Então, qual o motivo da existência dessa síndrome? Na prática, o que se observa é que a grande maioria dos insatisfeitos, na verdade, possuem pênis dentro dos limites considerados normais, mas que gostariam de tê-los maiores. Por quê? Os motivos são diversos: 1- Baixa da auto-estima por sentimento de inferioridade por crença de que seu pênis é menor que os de outros homens. 2- Trauma psicológico iniciado ainda na infância, por comparações com os pênis de outras crianças; às vezes, o trauma é induzido pelos próprios pais ao demonstrarem ansiedade em relação ao tamanho do pênis dos filhos. 3- Crença indevida que pênis grandes dão mais prazer a si e às parceiras ou que apenas pênis grandes poderiam proporcionar satisfação ou estímulo eficiente às parceiras. 4- Falsa idéia que as mulheres preferem homens com pênis grandes. 5- Auto-imagem masculina relacionada com o tamanho do pênis e capacidade erétil. 6- Transferem para o pênis a culpa por outras dificuldades ou inadequações sexuais.

Micropênis, hipospádias e epispádias, retração peniana nos lesados medulares, amputações parciais do pênis, defeitos pós-traumáticos e encurtamentos penianos por doença de Peyronie são as mais freqüentes indicações para as cirurgias de alongamento peniano. $\mathrm{O}$ alongamento peniano como procedimento estético ou cosmético é considerado experimental, reservado a centros médicos credenciados segundo as resoluções 196/96 do Conselho Nacional de Saúde e 1478/97 do Conselho Federal de Medicina. Os procedimentos cirúrgicos atualmente disponíveis para alongamento e aumento da circunferência peniana são os seguintes:

1- Secção do ligamento suspensor do pênis, uma estrutura fibroelástica inserida proximalmente na extremidade inferior da linha branca e porção superior da sínfise pubiana e distalmente na porção fixa, proximal, da haste peniana, cuja função é manter o grau de inclinação do pênis em ereção, ou seja, faz com que o pênis ereto aponte para frente e para cima. $\mathrm{O}$ ligamento é dissecado e seccionado logo abaixo da sínfise pubiana. Deve-se evitar a dissecção extensa, pelo risco de lesão de estruturas neuro-vasculares. Para evitar-se a readerência do ligamento ao periósteo, no espaço criado entre o corpo peniano e o púbis, enxerto de derme ou material sintético é interposto. Além disso, com o mesmo fim, emprega-se a tração peniana por meio de pesos pendurados ao sulco bálano-prepucial, intermitentemente, por 6 a 8 semanas. Esta técnica permite avanços de 1 a $4 \mathrm{~cm}$ da porção pendular peniana. Complicações como hematomas, infecção, deiscência da ferida operatória e hipoestesia peniana são infreqüentes. Readerência do ligamento suspensor do pênis ao púbis pode levar ao encurtamento do pênis. Embora não interfira na função sexual, esta técnica, por soltar o ligamento suspensor do pênis, faz com que este, em ereção, aponte para baixo em vez de para cima e para frente.

2- Lipectomia ou lipoaspiração suprapúbicas, indicadas nos pacientes cujo exuberante coxim adiposo suprapúbico sepulta parcialmente a haste do 
pênis. O ganho em extensão da haste peniana é relativo, pois apenas "descobre" a porção da haste peniana que estava sepultada pela gordura suprapúbica.

3- Avanço da pele inferior do abdome através de técnicas de zetaplastia e plástica Y-V, onde pode-se obter ganhos de até $2 \mathrm{~cm}$. As complicações possíveis são a deiscência da sutura, necrose do retalho, formação de retrações do pênis por cicatrizes hipertróficas e "escrotalização" do pênis, situação em que a pele do escroto avança sobre o segmento proximal da haste peniana e esta assume o aspecto "enrugado" do escroto.

4- Aumento da circunferência peniana por enxertos. O silicone líquido, aplicado sob a pele do pênis, foi tentado e logo abandonado pelos péssimos resultados obtidos (migração da massa de silicone, formação de nódulos subcutâneos, edema e adenopatia).

5- Aumento da circunferência peniana por injeção de gordura autóloga. Injetada entre o dartos e a fáscia de Buck, a gordura é obtida por lipoaspiração do abdome, regiões crurais e coxas. Apenas $30 \%$ da gordura injetada permanece no pênis após 1 ano. A necrose e reabsorção local causam assimetria da superfície peniana e formação de nódulos que comprometem a estética do órgão. Freqüentemente, novas injeções de gordura autóloga são necessárias para manter o resultado.

6- Aumento da circunferência peniana por enxertos de derme. Trata-se de um segmento de pele desepitelizada, retirado da região glútea ou virilha. $\mathrm{O}$ enxerto é interposto entre o dartos e a fáscia de Buck. Complicações como edema persistente, fístulas, infecção e hipoestesia peniana podem ocorrer.

Pelo exposto, as indicações puramente cosméticas, na maioria dos casos, não justificam os riscos dos maus resultados e complicações.

Os métodos não cirúrgicos, ditos naturais, são propagados pela mídia como seguros e eficientes. Os mais comuns são: 1- O emprego de um cilindro acoplado ao pênis que cria um vácuo, induzindo e facilitando o aporte sangüíneo e ereção por aumento da pressão interna dos corpos cavernosos. $\mathrm{O}$ aumento forçado, a longo prazo, da pressão intracavernosa, produziria o estimulo adequado para o alongamento e aumento da circunferência do pênis. 2- O emprego de dispositivos acoplados ao pênis, para exercer sobre este, força de tração no mesmo sentido do seu eixo, seja pelo uso de pesos presos ao pênis, seja pelo uso de equipamentos que se apóiam no púbis e na glande e são esticados, forçando o estiramento constante e prolongado do pênis, conferindo assim o estímulo de tração necessário para o alongamento da haste peniana.

É inegável que qualquer tecido submetido a tração adequada e prolongada, terá sua atividade histológica adaptada ao estímulo aplicado e tenderá 
a dilatar-se, alongar-se. Ambos os métodos são prolongados, algo dolorosos e não isentos de complicações locais como equimoses, lacerações e ulcerações. Ganhos, principalmente de comprimento são conseguidos. Porém, não se sabe se os resultados são permanentes nem se ocorre perda ou diminuição da função, tanto a curto quanto a longo prazo. Incidência de condições como alterações da sensibilidade, fibrose peniana, alterações tróficas e disfunção erétil é desconhecida. Não existem estudos adequados que suportem seu emprego nem que garantam manutenção dos resultados ou ausência de complicações. Portanto, consideramos arriscado e de benefícios discutíveis, por enquanto, o emprego dos métodos cirúrgicos e não cirúrgicos para fins cosméticos, razões pelas quais os proscrevemos até que passem pelo crivo do tempo e de estudos adequados. Diante de assunto tão delicado, pois envolve insatisfação com uma das mais fortes forças que impele o ser humano: a sexualidade, não podemos desprezar a segurança. No momento, o mais prudente e seguro é apoiar psicologicamente esses pacientes, aumentando sua auto-estima e grau de aceitação com o próprio corpo. Muitos são indivíduos com alterações outras da sexualidade que, mesmo que tivessem seus problemas com o tamanho do pênis resolvidos, continuariam a apresentar outras inadequações sexuais e não mais teriam o pênis para culpar.

\section{BIBLIOGRAFIA}

BISSADA, N. K. Penile reconstruction after total penectomy ou urethra-sparing total penectomy. J. Urol., 137:1173, 1987.

DA ROSS, C.; TELOKEN, C. Caucasian penis: what is normal size? J. Urol., 151:323, 1994.

EISENMAN, R. Penis size: Survey of female perceptions of sexual satisfaction. BMC Womens Health., 1:1, 2001.

FARIA, E. G. Cirurgias de aumento do pênis: $O$ que é verdade? Urologia Contemporânea, 8: 36, 2001.

HINDERER, U. T. Functional and aesthetic results in hypospadias repair with Hinderer's techniques. Aesthetic. Plast. Surg., 24:323, 2000.

HINDERER, U. T.; ESPINOZA, J. F. New technic of penis lengthening with girth augmentation in constitutional penile hypoplasia or in hypospadias. Cirurgia Plástica Ibero-Americana, 23:151, 1997.

JOHNSTON, J. H. Lengthening of the congenital or acquired short penis. $\mathrm{Br}$. J. Urol., 46:685, 1974.

KABALIN, J. N.; ROSEN, J.; PERKASH, I. Penile advancement and lengthening in spinal cord injury patients with retracted phallus who have failed penile prosthesis placement alone. J Urol., 144:316, 1990.

KELLEY, J. H.; ERAKLIS, A. J. A procedure for lengthening the phallus in boys with exstrophy of the bladder. J. Pediatr. Surg., 6:645, 1971.

MURTAGH, J. The 'small' penis syndrome. Aust. Fam. Physician., 18:218, 1989. 
PONCHIETTI, R.; MONDAINI, N.; BONAFE, M.; DI LORO, F.; BISCIONI, S.; MASIERI, L. Penile length and circumference: a study on 3,300 young Italian males. Eur. Urol,, 39:183, 2001.

REILLY, J. M.; WOODHOUSE, C. R. Small penis and the male sexual role. J. Urol., 142:569, 1989.

RIGAUD, G.; BERGER, R. E. Corrective procedures for penile shortening due to Peyronie's disease. J.Urol., 153:368, 1995.

SOCIEDADE BRASILEIRA DE UROLOGIA. I Consenso Brasileiro de disfunção erétil. São Paulo, BG Cultural, 1998.

WESSELLS, H.; LUE, T. F.; MCANINCH, J. W. Complications of penile lengthening and augmentation seen at 1 referral center. J. Urol., 155:1617, 1996.

WESSELLS, H.; LUE, T. F.; MCANINCH, J. W. Penile length in the flaccid and erect states: Guidelines for penile augmentation. J. Urol., 156:995, 1996. 